RAE-IC, Revista de la Asociación Española de Investigación de la Comunicación vol. 8, núm. 15 (2021), 53-69 ISSN 2341-2690

Recibido el 22 de agosto de 2020 DOI: https://doi.org/10.24137/raeic.8.15.3 Aceptado el 24 de noviembre de 2020

\title{
La autosuficiencia de la escritura audiovisual científica
}

The self-sufficiency of audio-visual scientific writing

Oliveira, Pedro Pinto de

Universidade Federal de Mato Grosso (UFMT)

ppo@terra.com.br

Forma de citar este artículo:

Oliveira, P. P. de (2021). La autosuficiencia de la escritura audiovisual científica. RAE-IC, Revista de la Asociación Española de Investigación de la Comunicación, 8(15), 53-69. https://doi.org/10.24137/raeic.8.15.3

\section{Resumen:}

Como una instancia central en el proceso de democratización de la ciencia, la comunicación es pensada a partir del poder de nuevas formas que puedan acoger el contenido científico. La reflexión aquí propuesta trata de la autosuficiencia de la escritura audiovisual científica con el surgimiento del ensayo audiovisual académico. Para comprender la autonomía de las imágenes, su ubicuidad, la dialéctica y también el montaje audiovisual aplicado a la construcción y comunicación del conocimiento, se aportan las consideraciones de Georges Didi-Huberman, Galvano Della Volpe y Walter Benjamin; se incorporan asimismo, las nociones de Alberto Manguel sobre la composición audiovisual autosuficiente como escritura académica y científica 
contemporánea; y de John Dewey se rescata el debate tanto sobre la cuestión ética de la democratización como sobre el lugar de la ciencia en la sociedad.

Palabras clave: teoría de la comunicación, filosofía, la ciencia, audiovisual, democracia.

\begin{abstract}
:
As a central aspect in the process of democratising science, communication is thought considering the strength of new forms to convey scientific contents. The proposed reflection approaches the self-sufficiency of audio-visual scientific writing with the emergence of the academic audio-visual essay. In order to understand images' autonomy, as well as its ubiquity, dialectics and audio-visual montage applied to the construction and communication of knowledge, we bring considerations of Georges Didi-Huberman, Galvano Della Volpe and Walter Benjamin. We incorporate also the notions of Alberto Manguel on self-sufficient audio-visual composition as contemporary academic and scientific writing. With John Dewey, we recall the debate both on the democratisation's ethical debate and the place of science in society.
\end{abstract}

Keywords: communication theory, philosophy, science, audiovisual, democracy.

\title{
1. INTRODUCCIÓN
}

El presente trabajo debate la autosuficiencia de la escritura audiovisual para la comunicación de los hallazgos de la ciencia. Se parte de las aprehensiones de la filosofía y del cine para reflexionar sobre la potencia del texto audiovisual de acoger los contenidos científicos. Se plantea un nuevo camino de experimentación en este tipo de escritura a partir de una defensa de la autonomía de las imágenes, su ubicuidad y dialéctica, en la convicción de que la comunicación de la ciencia en medios audiovisuales es autosuficiente y que trata de una vertiente de alta relevancia del hacer científico en el contexto contemporáneo.

Ya no se trata de pensar en la imagen como un simple complemento o, al revés, rebajar el texto verbal. La imagen y la palabra forman partes constituyentes de los sentidos, de 
las posibilidades de escrituras autónomas, a la vez que estas abren nuevos espacios a la discusión científica, con atención a la dimensión ética de la democratización de la ciencia. La discusión sobre las experimentaciones hechas con los lenguajes, los nuevos instrumentos tecnológicos y las nuevas escrituras, pertenecen al campo propio de la Teoría de la Comunicación. Se trata de un debate que está de acuerdo con el contexto de nuestro tiempo en una sociedad mediatizada. No se puede estar al margen de este proceso.

La intención principal, es contribuir con este oportuno debate en el mundo académico, tanto en el aspecto más general de los medios y fines, como también en la fundamentación teórica la cual sostiene la autosuficiencia de la escritura con la experiencia del ensayo audiovisual científico y los procedimientos metodológicos involucrados en su realización.

En el contexto contemporáneo, muchos investigadores de diversas áreas han empezado a incorporar el audiovisual como una "parte" de su comunicación científica, más allá de los artículos y libros - sus escrituras verbales-. A la comunicación audiovisual, sin embargo, todavía se la trata en muchos casos como un complemento a lo verbal, sin autonomía y autosuficiencia para comunicar los hallazgos de ciencia. Hay que indicar, no obstante, que ya se articulan nuevas relaciones entre la imagen y la palabra en combinación para la construcción del conocimiento.

En este ámbito destacase Carpentier (2018) cuya investigación sobre la intersección entre la ciencia y el arte subraya esas posibilidades de una articulación de la imagen y del texto verbal, sugiere aplicaciones útiles y creativas del audiovisual, pero todavía con un carácter complementario a la imagen.

A nosotros los académicos nos gusta mucho los textos. Son la esencia de lo que es la academia y así debería ser. Lo que defiendo es que debemos complementarlos con otras formas de comunicar la investigación. La forma visual es una de ellas, la exposición es otra. Ya hay un gran número de personas que vienen trabajando con lo que se llama investigación basada en el arte, es decir, una investigación que utiliza el arte para organizar la reflexión de modo a organizar la producción del conocimiento. No se trata 
solamente de una forma de comunicarse. Se trata de integrar la práctica artística a la producción del conocimiento. De verdad, nosotros somos creativos en la escritura y en la producción de investigaciones. Nosotros podemos ser también creativos en la utilización de otros recursos, como un repertorio artístico para comunicar nuestro conocimiento. Al mismo tiempo, podemos hacer uso de esta comunicación para avanzar en la reflexión sobre este conocimiento. La exposición me permite hablar al mundo exterior y alcanzar a un público que con el texto académico jamás alcanzaría (Carpentier, 2018. Youtube).

La propuesta que se presenta aquí se reitera, es la de un juego de suma de potencialidades. No se trata de ninguna manera de un debate estéril en el ámbito de un dualismo entre la defensa o la crítica de que una modalidad de escritura pueda ser más potente y pertinente que la otra, sobre todo porque partimos desde el reconocimiento de la centralidad de la palabra escrita. La discusión propuesta, es la de pensar en este modo diferente, autosuficiente y autónomo de la escritura audiovisual, que amplía las posibilidades de comunicación entre pares y con la sociedad en el contexto contemporáneo de democratización del conocimiento.

Dicho de otro modo, los objetivos planteados son: a) reflexionar sobre el potencial del ensayo científico audiovisual como fuerza comunicativa de imágenes en el contexto contemporáneo de los choques de la ciencia contra la negación del conocimiento y contra la proliferación de falsedades y b) señalar cómo esta escritura audiovisual es capaz de articular un discurso de inteligencia, autónomo, para comunicar ciencia a sus pares y también para insertar conocimiento científico, certificado, en la dirección de las personas implicadas en este mundo de los medios electrónicos digitales.

Los procedimientos metodológicos tienen dos vertientes: a) una investigación teórica cualitativa, a partir de los autores aquí mencionados y b) la aprehensión práctica de las experiencias con las escrituras de ensayos científicos audiovisuales que ya se han previamente realizado, mencionadas en las referencias bibliográficas y audiovisuales, destacando la autonomía de forma de comunicar la ciencia. La imagen y el montaje asumen una condición central y no meramente complementaria. 
Hoy nos parece evidente, existen resistencias que van más allá de pensar en la imagen solamente como algo complementario, entre ellas: a) condenar a priori la imagen como siendo "sospechosa"; b) confundir la natural manipulación técnica del instrumental tecnológico con la manipulación ideológica; c) el temor de "trivializar" la comunicación científica al menoscabar sus contenidos a un lenguaje "común" y "apelativo" o d) la simple comodidad de seguir comunicando de la misma manera, única, como se lo ha venido haciendo por cuatro siglos, conforme planteó el filósofo y físico Stephen Floor (2019) en un provocativo posteo en Twitter:

Nunca deja de sorprenderme que, como científicos, pasamos todos los días "innovando" y buscando descubrir nuevas cosas en el mundo y que, aun asi, haya una gran resistencia en cambiar la manera con la cual comunicamos la ciencia en el formato de un artículo para revistas de 350 años (Floor, 2019. Twitter).

La academia debería estar más atenta a los cambios que han transformado nuestro modo de ser y de vivir en una sociedad mediatizada. En este contexto, se está de acuerdo con el profesor João Carlos Correia, de la universidad de Beira Interior (UBI/Portugal), del campo de la comunicación y la cultura: la academia debe asumir el desafío de pensar en la presencia de la imagen hoy día en el mundo y contexto actual. Entre los aspectos de este desafío, está la reflexión acerca de lo que se examina sobre la comunicación científica a través de la escritura audiovisual.

La imagen va a continuar aumentando su importancia y la cuestión es: ¿vamos a dejar que esto ocurra sin reflexionarlo? ¿Vamos a dejar otra vez más que la universidad llegue tarde a los procesos sociales $o$, al revés, la universidad va a relacionarse con estos procesos sociales? La importancia de la imagen es un hecho. La relación de la ciencia con la opinión pública es una exigencia cada vez más grande (João Carlos Correia). ${ }^{1}$

\section{FUNDAMENTOS DE LA AUTOSUFICIENCIA DE LA ESCRITURA AUDIOVISUAL CIENTÍFICA}

El formato audiovisual científico es uno más en la comunicación de la ciencia, no reemplaza la palabra. A manera de decir del filósofo Didi-Huberman (2004), no hay más

\footnotetext{
${ }^{1}$ Testimonio del Profesor João Carlos Correia (Moreira; Oliveira, 2019).
} 
una imagen única, así como no habría una palabra única para expresar la totalidad de una realidad, sea cual sea. Se piensa, por ende, en la autonomía de las formas a disposición de la ciencia para comunicar sus hallazgos y reflexionar sobre los mismos entre sus pares $y$, también, como consecuencia, a la sociedad. Se puede llegar a considerar que esta investigación desde el campo de la comunicación pueda generar un impacto social más grande a partir de la experiencia de esta nueva forma de comunicar la ciencia: el Ensayo Audiovisual Científico.

La fundamentación teórica empleada para reflexionar acerca de la condición autosuficiente de la escritura audiovisual científica hace un acercamiento a la filosofía y al cine en tres vertientes de análisis: 1) el concepto de montaje de Georges DidiHuberman en su sugerencia de que se debe aprender a dominar el dispositivo de las imágenes para saber qué hacer con ese conocimiento y la memoria; 2) el abordaje de una estética científica con la concepción de Galvano Della Volpe, que plantea que la imagen fílmica constituida de forma e ideas determinadas, establecen su comunicación como un discursus de la inteligencia, tomando en cuenta las características específicas del material y de los procedimientos fílmicos y 3) las nociones de las mediaciones tecnológicas de Walter Benjamin, en su argumentación de que la "revolución tecnológica" precede al análisis entre el juego ilimitado de las formas y el juego ilimitado de los contenidos, que solo pueden ser resueltos "caso a caso".

Didi-Huberman, quien plantea su argumentación sobre el conocer a través de imágenes, convocando, entre otros autores, a los formalistas rusos del cine, en particular Sergei Eisenstein y el cineasta francés Jean-Luc Godard. No se entrará en discusión aquí sobre las distinciones teóricas y prácticas entre las escuelas/movimientos como el formalismo y el realismo, teniendo este último como referencia histórica el teórico francés André Bazin. Para efecto de la formulación que aquí se presenta sobre la autosuficiencia del audiovisual científico, queda entendido que el formalismo y el realismo son modos distintos de construir el conocimiento y de manipulación técnica de las formas de escritura audiovisual en la combinación de sus elementos de significación -cámara, iluminación, sonido, composición del escenario y edición-. Por ende, la yuxtaposición 
de planes, en la visión del formalismo, o el plano secuencia del realismo, son elecciones instrumentales de acuerdo con los fines en mente.

El valor del conocimiento, de acuerdo con Didi-Huberman (2004), no es intrínseco solamente a una imagen. De la misma forma, la imaginación consiste en una "involución pasiva en una sola imagen". Para el filósofo, se trata, al revés, de poner el múltiplo en movimiento, de no aislar nada, "hacer surgir los hiatos, las analogías, las indeterminaciones y lo que está más allá de ellas en la obra". La argumentación sostiene que el conocimiento es un proceso de montaje y, en el caso de las imágenes, en su yuxtaposición, lo entendemos como una noción-clave en la forma de la escritura audiovisual.

El autor destaca también, en ese proceso, que la imaginación no significa abandonarse a las especificidades de un único reflejo, como se tiene creído, y sí "la construcción y el montaje de las formas plurales relacionándolas". Se trata de un proceso aplicado al proceso de montaje de la escritura en secuencias de imágenes, en sus correspondencias a través de analogías o en su autonomía: lo que dice la imagen en relación y lo que dice por sí mismo. Didi-Huberman (2004), sin embargo, piensa en la validación de esta escritura por su valor ético: "el montaje solo es válido", afirma, "cuando nos permite acceder a las singularidades del tiempo, por su esencial multiplicidad".

El filósofo busca en la obra de Eisenstein el entendimiento de la relación entre el pensamiento en la acción reflexiva y el contexto donde actúa. Para el formalista ruso, "el pensamiento es un montaje y la cultura, el resultado de un proceso de montaje donde el pasado no desaparece, sino se reincorpora, reinterpretando el presente". Para Eisenstein, el arte no se reduce al registro o a la imitación de la naturaleza: el arte es el conflicto entre la representación de un fenómeno y la comprensión y el sentimiento del fenómeno representado.

Eisenstein, al destacar la esencia del montaje como un proceso intelectual, resaltaba que la yuxtaposición de las imágenes, los planos, crean significados. Para él, el montaje debe ser entendido en las relaciones constituidas, en una representación que penetra todas las imágenes y organiza la escritura de tal manera que se forma un todo. Una 
noción relacional, también, entre el escritor y el público, en la experiencia compartida de un tema. Con dicha idea aplicada a nuestra discusión, se puede ver el científico que habla con sus pares en el formato de la comunicación audiovisual de su tema, con contenido común a la comunidad académica de que es parte.

El montaje de la escritura audiovisual para el filósofo francés se ubica a la altura del pensamiento, en concordancia con el cineasta Jean-Luc Godard, para quien el cine fue hecho, en primer lugar, para pensar y, por ende, debería primero producirse como una "forma que piensa".

El montaje es el arte de producir esta forma que piensa. Procede, filosóficamente, como una dialéctica (como Benjamin y Bataille, a Jean-Luc Godard no le gusta citar a Hegel si no es para pervertirlo mejor): es el arte de reflejar la imagen dialéctica (Didi-Huberman, 2004, p. 204).

Didi-Huberman subraya que debemos comprender la dialéctica, en el sentido de una colisión desmultiplicada de palabras o imágenes. Las imágenes se chocan entre sí para que aparezcan las palabras y las palabras se chocan entre ellas para que aparezcan las imágenes. "Las imágenes y las palabras entran en colisión para que el pensamiento tenga lugar visualmente".

Es entonces cuando la imagen adquiere una legibilidad que surge directamente de las opciones del montaje: ésta se basa en una "contraposición de los inconmensurables" pero no por ello deja de producir un auténtico "fraseo de la historia" (Didi-Huberman, 2004, p. 205).

Como sistemas de significación aplicados a la representación y a la comprensión de un fenómeno de la ciencia comunicado a través de la escritura audiovisual científica, se ha pensado en las posibilidades de juntar las formas y contenidos. Los esfuerzos hechos en esta investigación apuntan hacia formatear el lenguaje audiovisual para así poder acoger la discusión científica, proponiendo construir y caracterizar el formato del ensayo audiovisual científico.

Existen distintos modos de pensar el proceso de montaje de la escritura audiovisual. La descripción y la discusión sobre estas variantes conceptuales y metodológicas no son los 
retos de presentados en este trabajo. Se intenta brindar una noción que también parte de la relación entre la filosofía y el cine, con el abordaje de una "estética científica" presentada en la concepción del filósofo italiano Galvano Della Volpe, quien plantea la imagen fílmica que se constituye por "forma e ideas determinadas que establecen su comunicación como un discursus de la inteligencia". Della Volpe toma en cuenta las características específicas del material y de los procedimientos fílmicos.

El material y los procedimientos fílmicos pueden verse, en esta aprehensión del audiovisual científico, como las bases metodológicas de la escritura. La materialidad se refiere a la que se toma por el escritor del extra-fílmico - el empirismo, las referencias, los conceptos y las operaciones de análisis - para el fílmico - las formas y los sistemas de significación-. Los principios fílmicos de cómo mostrar y cómo contar sostienen la organización y la combinación de las distintas estructuras discursivas del medio audiovisual y de sus camadas semánticas. Della Volpe comprende también que este camino entre extra-fílmico y el fílmico se da a partir del guion, de lo verbal, hacia otras fases del proceso, como la realización y la edición. Además, que el discursus de la inteligencia refleja la autosuficiencia de la escritura audiovisual en la articulación del pensamiento en las imágenes, las cuales son símbolos, ideas y formas bien determinadas de acuerdo con sus fines.

Della Volpe presenta su idea sobre lo que sería, entonces, la forma, el contenido y sus relaciones, desarrollando cuatro puntos de abordaje, según Dominique Chateau:

1) la imagen artística (filmica, etc.) se convierte en una forma en virtud de su carácter simbólico que funda, igualmente, su poder de expresión y de comunicación; 2) la forma, para que la comunicación sea efectiva, se concreta por ideas empíricas o "plenas", encarnadas en una pluralidad de formas determinadas y distintivas; 3) este "carácter pleno" autoriza la remisión de la idea puesta en forma a un contenido que "no puede ser sino lo que se dice sensible o experimentado, en general, y, en suma, la materia, lo particular, en el seno de lo cual la idea (lo universal) se define con precisión para ser "idea de alguna cosa"; 4) dado que la forma está en el principio de expresión, que las formas son lo intermediario que particulariza esta expresión y que el contenido es su referencia, 
hay una "funcionalidad recíproca de la forma y del contenido", a fin de cuentas unificados (Chateau, 2009, p. 79).

Walter Benjamin (2017) apunta para el "juego ilimitado de las formas y el juego ilimitado de los contenidos", pero busca un análisis que anteceda a esta infinidad de posibilidades de relaciones. El filósofo alemán destaca, entonces, las mediaciones, en el caso, las mediaciones tecnológicas. Asimismo, afirma que el examen debe hacerse a partir del contexto, de la situación, "caso a caso".

La cuestión de qué es significativo en una trama cinematográfica está tan escasamente resuelta como los problemas formales abstractos que han surgido de la nueva tecnología. Y esto prueba sobre todo una cosa: los avances más importantes y fundamentales en el arte no son ni un asunto de nuevo contenido ni de nuevas formas; la revolución tecnológica los precede a ambos. Pero no es casual que en el cine esta revolución no haya podido descubrir una forma ni un contenido apropiado para él. Porque resulta que con el juego ilimitado de las formas y el juego ilimitado de la trama la cuestión solo puede resolverse caso por caso (Benjamín, 2017, p. 30).

\section{COMUNICACIÓN Y CULTURA CIENTÍFICA: DESAFÍOS CONTEMPORÁNEOS}

En este trabajo se presenta la argumentación sobre la autosuficiencia de la escritura audiovisual para comunicar los hallazgos de la ciencia, sin olvidar que los desafíos están más allá de la reflexión teórica de ese modo de comunicar. Existen cuestiones desplegadas sobre las que hace falta debatir más y mejor. Son situaciones problemáticas que deben ocupar el campo de la comunicación en intersección con la cultura, el cine y la ciencia. Las Problemáticas citadas aquí como otras posibilidades para alargar el debate a partir de la discusión aportada aquí. ¿La cultura contemporánea requiere la presencia de discusiones científicas en el formato audiovisual? ¿Los modos de comunicación audiovisuales actúan como formas democratizadoras del conocimiento?

En el ensayo audiovisual para Tecmerin: Revista de Ensayos Audiovisuales de la Universidad Carlos III de Madrid con el título "Nuevas formas de comunicar la ciencia: la experiencia del ensayo audiovisual científico" (Moreira; Oliveira, 2019), se defiende la relevancia de la comunicación audiovisual en la ciencia hoy día y su importancia para la 
democratización del conocimiento. La escritura científica en formato audiovisual no "disminuye o trivializa el contenido de la ciencia", aunque el autor es el científico mismo, en su comunicación entre pares, en aquello que llamamos "vocabulario común" usado por los científicos para discordar o ponerse de acuerdo. Aun así, el público en general tendrá más acceso, interés y la posibilidad de comprenderlo en el contexto contemporáneo, aparentemente irresistible, de la sociedad de la comunicación por imágenes.

En su idea de democracia comunicada, el filósofo John Dewey (1970) apunta al rol de la comunicación como un requisito de la participación, para compartir el conocimiento. No puede existir un público, una comunidad, sin que las ideas sean comunicadas, que se vuelvan un dominio de la opinión pública. Así lo considera Thamy Pogrebinschi acerca de la noción de Dewey.

La opinión pública corre el riesgo de distorsionarse o limitarse por cualquier cosa que venga a obstruir o restringir la publicidad y, como consecuencia, perjudicar el discernimiento de las cuestiones relativas a la comunidad. De este modo, se hace necesario difundir y diseminar de manera absoluta los asuntos comunitarios. "Un hecho de la vida de la comunidad que no sea divulgado de manera a tornarse una posesión común es una contradicción en términos", dice Dewey. Es necesario que las informaciones comunales sean distribuidas extensa e intensamente, aunque no de manera aleatoria; deben germinar, crear raíces y fructificar para la propia comunidad al ser compartidas sus propias actividades y consecuencias. El medio que posibilita la publicidad y la diseminación de las informaciones comunitarias es, al final, la comunicación (Pogrebinschi, 2005, p. 141).

Otro aspecto que brinda Dewey para la reflexión que se hace en este análisis se refiere a la cuestión de comunicar, en la medida del posible, lo que es reciente, actual y contemporáneo, respetándose las temporalidades propias de la investigación científica. La formación de la opinión pública depende de los resultados de la investigación social, de modo que tardar en divulgarlos más allá del tiempo necesario de la investigación hasta la comunicación de sus hallazgos puede afectar la constitución en lo que se tornará la opinión del público sobre los hechos presentes en una comunidad. El científico debe, 
por ende, comunicarse con sus pares, así como abrir y ampliar los modos de comunicación con la sociedad.

¿De qué sirve producir resultados y conclusiones a partir de una investigación que tenga por objetivo ser la más amplia y profunda si los mismos no se dan a conocer para el público? ... Más allá de eso, al mismo tiempo en que la comunicación saca las conclusiones de la investigación desde un pequeño círculo de científicos sociales e investigadores para el seno de la comunidad, también es ella que trae para este pequeño círculo y para estas pocas personas el material bruto que debe ser trabajado, es decir, los datos sobre los hechos y eventos que ocurrieron en la comunidad (Pogrebinschi, 2005, p. 143).

Finalmente, vemos que la idea de Dewey, del año 1935, sobre las responsabilidades de la cultura científica es muy actual. La cuestión de la democratización del conocimiento está en el centro de las transformaciones de esta cultura. "La cultura que permite a la ciencia destruir los valores tradicionales, aunque no confíe en su poder de crear otros, es una cultura que se destruye a sí misma".

El desafío es ampliar las formas de comunicación con el "Otro", lo que no significa perder la autonomía del espíritu científico o "popularizar" sus contenidos.

La necesidad ahora no es convertir los hombres de la ciencia en cruzados de causas prácticas especiales. De la misma manera que el problema del arte es unir la inherente integridad del artista con el apelo imaginativo y emocional de las ideas, así es la presente necesidad de reconocimiento por los hombres de ciencia de la responsabilidad social de la difusión contagiosa de la actitud científica, lo que no se dará sin el abandono, una vez por todas, de la creencia de que la ciencia se aparta de todos los otros intereses sociales, como siendo poseedora de una peculiar sacralidad (Dewey, 1970, pp. 238-239).

\section{EXPERIMENTACIONES METODOLÓGICAS}

Se ha tratado en esta investigación de una escritura autosuficiente DE la ciencia, no de distintas escrituras SOBRE la ciencia - películas de ciencia-ficción, documentales o reportajes de divulgación científica, entre otras escrituras-. 
El proceso de montaje del ensayo audiovisual científico parte de la palabra hacia las imágenes en sus fases de realización y edición, abriéndose para las nuevas posibilidades de la comunicación más allá del audiovisual. El guion del ensayo también se presenta como otra posibilidad de comunicación científica. Aunque sea una fase del montaje audiovisual, el guion contiene el pensamiento del autor completamente. El artículo, por lo tanto, puede tomar la forma de un guion.

Esta experiencia está en proceso: se realizó un ensayo audiovisual científico sobre una categoría de figura pública que actúa en la política y en los negocios de la agricultura y pecuaria en Brasil: el agropolítico. El guion del ensayo se publicó en un libro lanzado por el Grupo de Representación de la Imagen y Sociabilidad (GRIS) de la Universidad Federal de Minas Gerais (UFMG), que coordina la Red Interinstitucional de Acontecimientos y Figuras Públicas.

En la publicación de los estudios presentados, el desenlace tradicional de nuestro trabajo sería la conversión/traducción del ensayo en forma de texto estándar, poniendo en palabras las imágenes visuales y explicando los pasajes. Este escrito se aventura a mantener el guion como un guion, sometiéndolo a revisión por pares en su contenido y forma. Por su formato, difiere de un artículo, pero contiene (debe contener) toda la información que se debe presentar sobre los resultados de una investigación. El ensayo audiovisual y el guion del ensayo son nuevas formas de comunicar la ciencia, que se suman a las formas tradicionales en el compromiso del científico de democratizar el conocimiento que produce.

Se busca una nueva forma de escritura, y se trata de un experimento. Todavía no hay protocolos y normas establecidas para su construcción. Así pues, el guion contiene claramente, en su formato, indicaciones híbridas entre los guiones cinematográficos y publicitarios, desde la perspectiva de la Televisión e Internet (Oliveira, 2020, p. 118).

\section{CONSIDERACIONES FINALES}

Conforme se va reiterando, los esfuerzos puestos en este trabajo se dan en el sentido de proponer una discusión sobre la autosuficiencia de la escritura audiovisual para comunicar la ciencia. 
El conocimiento y los saberes son plurales. La Ciencia, el Cine y las otras Artes son sistemas de símbolos a los cuales nos podemos acercar para formatear, sin disyunciones, los conocimientos científicos. Ya no se trata de poner de un lado la belleza, la intuición y la emoción y, de otro, la verdad, la racionalidad y el saber. Ninguna de esas propiedades está restringida solamente al arte o a la ciencia y todas son insuficientes para distinguirse con relación a las demás. El reto más común de la Ciencia y de las Artes es la construcción de la comprensión de los mundos por medio de los sistemas de símbolos y el valor de cualquier de ellas depende de la corrección de las construcciones realizadas. La memoria, la razón y la imaginación se enredan completamente. Si la ciencia parte de la vida, de la naturaleza, también de ahí debe partir la película científica (Moreira y Oliveira, 2019).

Al fin y al cabo, se considera conveniente destacar que el ensayo científico es una escritura en construcción. En el aspecto institucional, no hay todavía los protocolos y normas que orienten sus estándares de aceptación por la comunidad científica para su publicación. Lo que se tiene a disposición en este momento, son experimentaciones de ensayos de audiovisual científico y movimientos iniciales de algunas publicaciones que empiezan a abrir espacios para esa forma de escritura de los contenidos científicos y no solamente como simples producciones técnicas y artísticas. Ese movimiento de acogimiento del audiovisual científico se da, notablemente, en las revistas digitales del campo de la comunicación, del cine y de la cultura.

Es relevante distinguir en el ámbito latinoamericano y de la Península Ibérica algunas experiencias y proyectos de publicaciones de video-ensayos, como la Revista Tecmerin, en Madrid; el Laboratorio de investigaciones y aplicaciones de semiótica de la Pontificia Universidad Católica del Perú (PUCP) y la labor de Transit: cine y otros desvíos, un proyecto en Barcelona, fundado por Carles Matamoros, Covadonga G. Lahera y Cristina Álvarez, entre otros. La compilación de esas experiencias latinoamericanas e ibéricas es parte de un proyecto de maestría en el Grupo de Investigación Multimundos, ligado al Programa de Posgrado en Estudios de Cultura Contemporánea (ECCO) de la Universidad Federal del Mato Grosso (UFMT). 
Se trata de esfuerzos que han sido emprendidos para ensanchar la discusión sobre la emergencia del ensayo audiovisual científico, identificando tanto las experiencias de producción en el contexto latinoamericano y de la Península Ibérica como la construcción y diseminación del conocimiento a través de esta forma de comunicación.

Alberto Manguel (2001) nos recuerda que Aristóteles sugirió que todo proceso de pensamiento requiere de imágenes. Los ensayos audiovisuales o video-ensayos se han convertido en una apología al pensar en imágenes, confirman que el conocimiento puede ser plasmado en una composición audiovisual que responda a los parámetros de la redacción académica y científica; pero, sobre todo, demuestran ser una forma de comunicación en disposición al otro, sus audiencias y lectores actuales, sean estos investigadores y personas dentro del campo de la academia, o aficionados interesados en satisfacer su búsqueda por experiencias de lectura cada vez más innovadoras e interactivas (Sevilla y Oliveira, inédito).

La integración práctica de este tipo de escrituras audiovisuales al contenido de revistas digitales, en especial aquellas catalogadas como científicas o académicas, representa un paso más hacia una mayor aceptación y confianza en la imagen, lo cual genera un futuro esperanzador para estos géneros como divulgadores de conocimiento.

Evidentemente, aún queda abundante espacio para seguir avanzando en la reflexión y producción de conocimiento respecto a esta modalidad de redacción y pensamiento audiovisual, así como en la búsqueda de espacios que lo promuevan, en especial dentro del contexto latinoamericano y la Península Ibérica.

A los que estén interesados en conocer más sobre lo que aquí se debate en palabras, se le puede leer por imágenes en el ensayo audiovisual científico que proponemos publicado en la Revista Tecmerin (Moreira y Oliveira, 2019).

Otra sugerencia es la experiencia de ensayo audiovisual que se realizó sobre los hallazgos de una investigación sobre la nueva categoría de figura pública de la política y de los negocios del mundo rural en Brasil, el agropolítico (Oliveira, 2019). 


\section{REFERENCIAS BIBLIOGRÁFICAS}

Benjamin, W. (2017). Mediaciones. Madrid: Biblioteca Nueva.

Carpentier, N. (2018). Nico Carpentier: Arte e ciência da paz. Recuperado de https://www.youtube.com/watch?v=COXCZ5sbzN8

Chateau, D. (2009). Cine y filosofía. Buenos Aires: Colihue.

Della Volpe, G. (1967). Lo verosímil fílmico y otros ensayos. Traducción de Alberto y Juan Antonio Méndez Borra. Madrid: Editorial Ciencia Nueva. [Título original: II verosimile filmico e altriscritti di estética].

Dewey, J. (1970). Liberalismo, liberdade e cultura. São Paulo: Editora USP.

Didi-Huberman, G. (2004). Imágenes pese a todo. Barcelona: Paidós.

Floor, S. (2019). It never ceases to amaze me that as scientists we spend all day "innovating" and trying to discover new things in the world, yet there's intense resistance to changing the way we communicate science from a 350 year old journal article format. 16 de julio de 2019. 11:12 am. Twitter: @stephenfloor. Recuperado de https://twitter.com/stephenfloor/status/1151147723925573632

Manguel, A. (2001). Lendo imagens: uma história de amor e ódio. Traducción de Rubens Figueiredo, Rosaura Eichenberg e Cláudia Strauch. São Paulo: Companhia das Letras. [Título original: Reading pictures: a history of love and hate].

Moreira, B. D. y Oliveira, P. P. de (2019). Nuevas formas de comunicar la ciencia: la experiencia del ensayo audiovisual científico. Tecmerin. Revista de Ensayos Audiovisuales, [S.I.], 2.

Oliveira, P. P. de (2019). O mundo rural e o cultivo do agropolítico no Brasil. Recuperado de http://www.fafich.ufmg.br/gris/2019/06/24/o-mundo-rural-e-ocultivo-do-agropolitico-no-brasil/

Oliveira, P. P. de (2020). Roteiro do ensaio audiovisual científico: mundo rural e o cultivo do agropolítico no Brasil - a semente de Mato Grosso. En V. França, P. Simões y 
D. Prado (Org.). Celebridades no Século XXI: Diversos perfis, diferentes apelos. Belo Horizonte, MG: PPGCOM. v. 2.

Pogrebinschi, T. (2005). Pragmatismo. Teoria social e política. Rio de Janeiro: Relume Dumará.

Sevilla, N. M. y Oliveira, P. P. de (Inédito). Video-ensayos: pensar académicamente en imágenes y en relación con "el otro". 